\title{
Place-Based Philanthropy and Measuring Community Well Being in the Age of COVID-19
}

\author{
Frank Ridzi ${ }^{1}$ \\ Received: 9 December 2020 / Accepted: 26 April 2021 / Published online: 5 May 2021 \\ (c) The Author(s), under exclusive licence to Springer Nature Switzerland AG 2021
}

\begin{abstract}
Place-based philanthropic organizations have long defined their value in terms of ability to improve well-being in the communities they serve. Desire to quantify and prove this impact has led such charities to be interested in and even invest in measures of community well-being. In this paper I explore how the onset of the COVID19 pandemic has affected local philanthropy's relationship with data and information by increasing public awareness of community data as a tool for describing rapidly changing community needs, raising expectations for an expedited connection between data analysis and action, and compelling civic leaders to engage in scenario planning. I draw on the case of Syracuse, NY to illustrate how the presence of a real time collaborative data infrastructure presents promising opportunities to address the data needs of place-based philanthropy when it comes to monitoring and acting to improve community well-being in the COVID era.
\end{abstract}

Keywords COVID-19 · Philanthropy $\cdot$ Community indicators $\cdot$ Community wellbeing $\cdot$ Place-based funders

\section{Introduction}

The onset of COVID-19 in 2020 has been a monumental disruption to daily life in a wide variety of ways. While most of these have been characterized as negative (such as death, illness, social isolation and economic crisis) there has also been a sense that some positive, or at least less clearly negative, outcomes have also accompanied the pandemic. Among these have been the rapid shift to a virtual work environment and the increasing use of online and home delivery services (Kasper \& Marcoux, 2020). Along with these shifts some have speculated that we may experience a silver lining in that new technologies, efficiencies and processes may emerge from this experience that will change our expectations and create new ways of doing business that will

Frank Ridzi

ridzifm@lemoyne.edu

1 Central New York Community Foundation, Le Moyne College, Syracuse, NY, USA 
remain in place even after the pandemic has subsided (Petrock, 2020). In this paper I explore one such possible change by examining how the onset and persistence of the pandemic may be changing the nature of how we interact with and what we expect from data. Specifically I examine how the increasing prominence of public health data as a focal point for community understanding of the nature and magnitude of local danger reframes the data that has been traditionally available as far too out of date to be of use. Furthermore, the quick action that government has taken in response to real time data has reinforced the importance of speed when moving from data analysis to action. Finally, the daily uncertainty and spectacle of the pandemic has raised expectations that all future oriented planning take place within the framework of considering multiple competing scenarios. Each of these changing expectations about data presents unique challenges that will force philanthropy to evolve if it is to establish and maintain an identity as data-driven and well-informed. As I consider what these developments mean for philanthropy I look at the historical relationship place-based funders have had with data and how these relationships will experience pressure to change given the new pandemic-era expectations about data. I conclude by looking at this scenario within a single community that provides one way forward as an example of what is possible.

\section{Place-Based Philanthropy and Community Data}

Philanthropy, and more specifically local or place-based funders such as community foundations, United Ways, and local family foundations, have long espoused the mission of improving community well-being. Articulated in their mission statements, grant making practices, policy advocacy work, and efforts to convene community leaders around pressing social problems, these place-based philanthropies have carved out a market niche and established themselves as agents of change and community leadership that offer an opportunity for donors to participate in an active agenda aimed at continued improvement in local quality-of-life (Mazany \& Perry, 2014).

These organizations have often described themselves as anchor institutions that, much like local hospitals, universities and other historic landmarks, are tied to their communities as part of their identity and, as such, the measure of their own success is inextricably linked with the success of the communities to which they are bound. For this reason, unlike funders that are national or international in scope and can choose to focus on specific content areas such as child health or education, place-based philanthropy has more often than not tied it's overall value proposition to its intimate knowledge of community needs and adept skills at leveraging local resources to address those needs (Leonard, 2014; Ridzi \& Prior, 2020).

Local philanthropies that have used community well-being as their barometer for impact have employed both subjective and objective measures. Annual reports abound with anecdotal stories of the ways in which individual grants or projects have changed the lives of families or individuals in positive ways. This is often accompanied by subjective assessments about how the existence of such programs will undoubtedly improve the overall quality of life. However, it is often said that 
stories move the heart but data moves the head. Donors seeking to decide how to disseminate their limited resources among seemingly unlimited needs and board members who are known to take a more business-minded approach have increasingly pushed for more objective measures of philanthropic impact. This pressure has been framed in the context of persistent poverty, low performing schools, and other social ills for which public data shows that problems have not been solved despite many years of philanthropic action and numerous anecdotal stories of community impact (Katz, 2005; Ridzi, 2012).

The push for more objective measures of local philanthropic impact has lead a number of community based philanthropies to invest in community indicator projects and other efforts to quantify community quality of life in areas where improvements have been made (Ridzi \& Prior, 2020). In this way, place-based funders have seen a strong ally in the community indicators movement and there has been increasing cross pollination of ideas between such funders and other experts who work in the area of community indicators such as local government, community planners, academia, and data specialists (Stevens et al., 2019).

As with so many other things, the onset of the COVID-19 pandemic, however, has created a new landscape which promises to alter existing relationships between philanthropy and measures of quality of life. As I will explore in the following pages the pandemic has increased public awareness of community data as a tool for describing rapidly changing community needs, raised expectations for an expedited connection between data analysis and action, and compelled civic leaders to engage in scenario planning. I will explore how each of these changes presents a challenge to the traditional ways in which place-based philanthropy has approached measures of community well being related to their work. Finally, I will draw on the case of Syracuse, NY to illustrate how the presence of a real time collaborative data infrastructure presents promising opportunities to address the changing data needs of place-based philanthropy when it comes to monitoring and acting to improve community well-being in the COVID era.

\section{Covid-19 and the Increase in Public Awareness of Data}

\section{Pandemic as Accelerant}

COVID-19 has been widely viewed as an accelerant because it is seen not so much as a force that changes things in unpredictable ways but rather as a force that accelerates or speeds up changes, transformations and conditions that are already in progress (Zolli, 2020, 1). This is perhaps most visible in the health sphere where people already suffering from compromised health or chronic conditions have seen their health decline expedited by contracting the coronavirus. Covid-19's characteristic nature as an accelerant has also been pointed out by business scholars as it has accelerated already in progress economic shifts. Bricks and mortar stores were already losing market share to online shopping such as Amazon and this pattern has been hastened. Similarly, direct to home services such as grocery delivery and streaming services such as Netflix and Hulu had already forced older competitors such as 
Blockbuster out of the market but these services have seen an even steeper climb in popularity. By some reports, COVID-19 has "accelerated the shift away from physical stores to digital shopping by roughly five years" (Perez, 2020). Relatedly, business models that were already wounded in the globalizing and increasingly online economy are now faced with the realization that these wounds may now be mortal. This is true in the for profit sector as well as the non profit sector where "COVID-19 threatens to be an extinction-level event for nonprofits" (SeaChange, 2020, 7). Estimates appearing in such places as The Washington Post and the National Council of Nonprofits website reported that between 10 and $40 \%$ of nonprofits might not survive the pandemic (Delaney, 2020; McCartney, 2020). The entire nonprofit business model is being called into question as donations reach their limits and state and federal funding sources dry up (New York Council of Nonprofits, 2019). As Korn et al. $(2020,1)$ point out, another major nonprofit player, colleges, are also struggling under the strain of the COVID-19 pandemic:

"For many schools, the pandemic is exposing flaws in their own business models. Even before the virus hit, many colleges and universities were running on razor-thin margins, with $30 \%$ of those rated by Moody's Investors Service showing operating deficits."

As they go on to explain, the pandemic has accelerated a trend that was already well underway:

“Before the pandemic, about 100 of the nation's 1,000 private, liberal-arts colleges were likely to close over the next five years, predicted Robert Zemsky, a professor at the University of Pennsylvania's graduate school of education, in "The College Stress Test," a book published in February. He now says 200 of those schools could close in the next year. Schools should expect a $15 \%$ decline in enrollment next fall and a $\$ 45$ billion decline in revenue from tuition, room and board and other services, according to the American Council on Education, the nation's largest advocacy group for colleges and universities. Some administrators say those projections are too rosy."

\section{Pandemic as Accelerant of Cl}

As with major industry and the nonprofit sector, the COVID-19 pandemic can also be seen as an accelerant for the field of community indicators and the integration of Community Indicators and Performance Management (CI-PM). Looking at Community Indicators to assess the position and progress of a community's quality of life and then incorporate these data into governmental and non-profit decision making with respect to policy and programs had been on the rise since the early 2000 s (Community Indicators Consortium, 2020). Numerous communities have set goals in such areas as environmental sustainability, health and education and produced dashboards to track their progress (see for instance Barrington-Leigh, 2017; King, 2017; and Powell, 2020). 
COVID-19 has increased public attention to the value of dashboards and using data to make decisions. Executive branch leaders (mayors, governors, the White House) pledged to be guided by data. This commitment even extended to major league sports. In the words of Dr. Thom Mayer, the NFL's player's union's medical director, "We'll go anywhere the science takes us and nowhere the science doesn't" (Belson \& Drape, 2020, 33). The US populace actively watched as these high profile leaders or their surrogates (such as the CDC and county health departments) delivered often daily briefings on the current status of COVID-19 cases, filled hospital beds and COVID-related deaths. This often resembled the somber spectacle of President Franklin D. Roosevelt's fireside chats but, instead of being broadcast via radio, they were broadcast on television and online where the presence of charts and dashboards with data were more than mere props - they were the center of focus for the discussion and updates (Moriarty, 2020; Idli, 2020; CNN Wire, 2020).

The rapid pace with which data were collected, tabulated, analyzed and publicly presented seemed to be at light speed compared with historic practices in the community indicators field, even in the case of the most developed indicator structures such as that of education and public health. For instance, it was not uncommon for communities to release public health reports that would focus on multiple years of trends and use the most recent data available - which would often be almost three years old before they were even made available to the public by state or federal sources (Volz et al., 2019). While this was state of the art practice and allowed communities to adjust their public health and other infrastructures to address slowly developing public health concerns, the entire paradigm was radically transformed with the onset of COVID-19. Rather than a long-delayed look back, the world began to expect such daily updates as featured in the dashboard displayed by the Hopkins, 2020 Coronavirus Resource Center (Hopkins, 2020). This seemingly live dashboard featured confirmed cases of COVID-19 and deaths as well as rankings of these by geography for both a global and US display. In addition to helping to highlight where the pandemic was having its worst impacts the dashboard featured a map indicating number of cases by location. Rather than an outlier, this now iconic dashboard, featured on national media, set a new standard that was emulated elsewhere. The New York Times launched its own version of an online dashboard to monitor trends across the nation and in key cities (New York Times, 2020). Furthermore, local communities also created their own COVID-19 dashboards that focused on trends in their own municipalities and allowed real time tracking of things such as active cases, deaths and recoveries by local towns and cities (Syracuse-Onondaga County Planning Agency, 2020).

While focused on indicators related to a specific public health crisis, the proliferation of COVID-19 data dashboards has opened up a pandora's box when it comes to the public's expectation of local governments and philanthropic leaders. The rapid mobilization of and sustained support for COVID data has set the new gold standard for what the public will expect when it comes to using data to identify the nature of and quantify the magnitude of social problems. For place-based philanthropy that has established a niche identity as having their finger on the pulse of local community needs (Leonard, 2014), nothing less than a real time ability to monitor these needs will seem state of the art from now on. As with other trends noted above, this 
is not an entirely new phenomenon. Indeed community indicator professionals have for some time bemoaned the problematic nature of an attenuated timeline between data collection and data availability and taken steps to make expedited data available (Patten \& Lyons, 2009; Crawford \& Ridzi, 2020; Summers et al., 2020; Davern et al., 2020; Ridzi, 2020). This is of particular importance when local philanthropy and other community leaders are seeking to take rapid action in response to emergent community needs.

\section{Increased Expectations for Rapid Connection From Data to Action}

With the onset of COVID-19 came a heightened sense of urgency about response. The Council on Foundations, the most prominent philanthropy association in the US, issued a call to action for the field of philanthropy articulating the "critical need to act with fierce urgency to support our nonprofit partners as well as the people and communities hit hardest by the impacts of COVID-19 (Council on Foundations, 2020, 1)." Over 780 organizations signed on to the pledge issued by the Council and committed to greater flexibility, less reporting and loosening of other restrictions. In addition the commitment included the promise that emergency needs would be addressed and accompanied with regular communication about philanthropic decision-making and response. For foundations seeking to be data-driven, this commitment promised an expedited approach to discerning community needs and taking action to address them.

The rush to action based on data was not an artifact of the philanthropic sector alone; state governors began using community health indicator data to put travel bans on people from states where outbreaks were occurring. The federal government did the same thing in terms of travelers from other nations. Local governments used the data to decide on whether to close schools, permit indoor dining, or allow golf courses to be used. Just as importantly, these were not one time decisions but rather daily "game time" decisions (similar to the way that coaches wait until just before a sporting event to discern whether a star athlete who has experienced illness for instance is healthy enough to play). In similar fashion, school superintendents would monitor data to set school start dates and then monitor and respond to outbreaks (often by switching to online learning) in a comparable way to the historical use of snow days (i.e. cancelling school on days with inclement weather).

The importance of real time data that had increased in visibility within the context of the COVID-19 pandemic was highlighted by the uproar when the supply of national data was disrupted. The White House sought to move the data collection and reporting structure from the Centers for Disease Control and Prevention (CDC) to the department of Health and Human Services. This resulted in delays and data problems which drew major criticism (Whelan, 2020). As community decision makers shared, the data were a way to see what was actually happening in their communities and to take action accordingly:

"The hospital data is important because it helps determine how much Remdesivir, a key antiviral treatment for Covid-19, the federal government distributes 
to each state. But hospitals also need to see consistent data from other hospitals in their region so that they can deploy enough health-care workers and beds in certain areas and respond to outbreaks by providing doctors and nurses with sufficient protective equipment.

'We use that data for a lot of different reasons, and one is to forecast and predict onwards not just the space capacity but the right number of workers, the right numbers of supplies,' Dr. Talbot said. 'It's also not just for the patients but for the community: Are we safe to start and relax the interventions? Are we still a hot spot? We really need to have that data to see what's going on.' (Whelan, 2020, 1)."

In the fashion described above, data became more than evidence to justify action; data were the main input when determining how to act. Nonprofit and other community leaders became more dependent on the flow of quantitative data, rather than more subjective and qualitative insights since their interpersonal interactions with clients and patrons was severely constrained. Using the metaphor of a pilot flying through a cloud, we have lost the ability to see out of our windows and we are flying more by our instrument panels, in this case, our dashboards.

This new paradigm challenges existing community indicators infrastructures and the ways in which local philanthropy has used them to respond to community needs. In the past, foundations had the luxury of time and could engage in extensive periods of analysis and stakeholder engagement before deciding on a course of action. However, in the age of COVID-19 the entire cycle of problem identification, action and evaluation of impact has been expedited. In essence the entire scientific process could be seen to speed up nationally. One observer noted:

"As scientists race to understand the coronavirus, the process of designing experiments, collecting data and submitting studies to journals for expert review is being compressed drastically. What typically takes many months is happening in weeks, even as some journals are receiving double their normal number of submissions.” (Tingley, 2020, 16)

In the more applied and social realms of science, such as scientific approaches to policy making and public administration, this same expedited timeline has been evident. Regardless of whether a standard timeline for moving from data analysis to action emerges, one thing is certain; expectations for speed and urgency have been elevated during the COVID-19 pandemic and place-based philanthropy seeking to be identified as having their finger on the pulse of their local communities and taking appropriate, timely, action will no longer have the luxury of relying on data sets that are a year old or more as has been common in the past.

\section{Heightened Importance of Scenario Planning}

While data and action have seen an expedited rate of connection, resources are ultimately limited when it comes to taking action, even for the philanthropic sector. As a result, the prolonged experience of the COVID-19 pandemic has led to an increasing 
interest on the part of philanthropy in conducting scenario planning so as best to determine how to most effectively deploy its limited though considerable resources. As early into the pandemic as April 2020 Deloitte's Monitor Institute began reaching out to foundation executives (among other nonprofit leaders) to begin thinking through potential future scenarios as the COVID pandemic continued to unfold. The goal was to develop guidance informed by "futures-thinking" to help funders and other nonprofit leaders to: " (1) consider the critical uncertainties of the moment, (2) reckon with the difficult, new "truths" emerging from the pandemic, and (3) explore possible future scenarios that may emerge over the next 12-18 months (Kasper \& Marcoux, 2020)." The result of this work was a detailed report that outlined four possible scenarios ranging from a rapid return to normal to a much scarier scenario in which we never manage to bring the virus under control and the nation is plunged into a decade-long effort to rebuild a shattered society. For each scenario there is a different call for philanthropy to take action. In the mildest scenario, it may behoove funders to conserve their resources for later use so that they have "more "dry powder' available to push for reform on the issues they care about" after the worst of the pandemic has passed (Kasper \& Marcoux, 2020, 12). In the second, worse, scenario, funders are warned they should expect to be called upon to heal tears in the social fabric that emerge as tensions among various groups in society ignite under the stress of the crisis. In a third and still worse scenario, funders should anticipate heavy pressure from state and local governments that have exhausted their resources and are turning to philanthropy for bailouts. In the worst case scenario, the nation is plagued by a long term pandemic that cripples the economy and government. In this case, philanthropy is never really able to get beyond addressing basic needs in their communities. Eventually, there may be opportunities to help by funding policy and systems-level change as the nation rebuilds (Kasper \& Marcoux, 2020).

Looking at the scenarios Delotitte produced in succession in some ways mirrors Maslow's (1943) hierarchy of needs. If the pandemic is relatively short lived, basic needs will be soon met and place-based funders can concentrate on higher level needs like greater efficiency and community improvement. In this sense the mantra, "never let a good crisis go to waste" can characterize funder opportunities to push for refinements in local policy and systems infrastructures. However, if the pandemic persists, funders will be under increasing pressure to use their resources to address unmet basic human needs (the lowest level of Maslow's hierarchy), even if this means spending their corpus. Such pressures may be further exacerbated by the likelihood that philanthropy employees will be relatively insulated from the harshest impacts of the pandemic, in stark contrast to their nonprofit brethren who are likely to suffer greatly (Kasper \& Marcoux, 2020).

This increase in future-oriented thinking should be no surprise since scenario planning has historically increased in times of great uncertainty such as with the military following world wars (in the context of rapid development of weaponry and uncertainty of global alliances) or in the case of the oil crisis in the 1970s or following the September 11th tragedy (Wilkinson \& Kupers, 2013). When scenario planning is used within strategic planning, the idea is to get an organization to think of some likely crises that may happen based on who the organization is, what they do, who they serve, how they serve them, and where they're located, etc. While 
organizations can never plan for all possible unknowns, scenario planning can at least help prepare the organization for a crisis before it happens.

When it comes to strategies of scenario planning, in the general genre of futurism there is a wide variation of approaches and no clear gold standard, although there are definitive patterns. For instance, some approaches such as Trend-Impact Analysis (TIA) tend to be more statistics- and data-driven, related to forecasting, as opposed to other more speculative approaches (Bradfield et al., 2005). However, for place-based funders that seek to maintain their status as data driven organizations with their finger on the pulse of community needs, mere speculation and anecdotal data input hardly seems sufficient. Rather, what the more data driven scenario planning approaches require is Community Indicators that are granular enough to be able to notice fluctuations in need as they react to unfolding events and the ability to forecast the continuation of or divergence from these patterns as new events unfold. For instance, as a community addresses the COVID-19 impact there are a wide variety of secondary effects such as people losing jobs and childcare centers going out of business. Furthermore, as people struggle to pay their rent, state governments and even the Center for Disease Control and Prevention put moratoriums on evictions. With all of these pandemic side effects and policy responses occurring within the course of a year, data need to be granular enough to monitor trends in local needs as they rise and fall in response to local and national action. Much of the publicly available data infrastructure on which community indicators are built, such as the US Census and federal government data sources such as the Bureau of Labor Statistics and Department of Health and Human Services, are released with annual time intervals which would mask all of these changing needs in a single yearly average. Looking at an indicator such as Food Stamps receipt, for instance, on an annual basis might simply show an overall rise for the year rather than periodic rises and falls as various local efforts to provide food kick into action and innovate to address local needs. Similarly, looking at the need for housing on an annual basis would not yield any insight into how this demand decreased as a result of government mandated moratoriums on evictions over the course of several months. Indeed, data driven scenario planning requires a new data infrastructure that most Community Indicators projects sponsored by place-based funders are woefully ill equipped to provide.

\section{Post COVID-19 Expectations Demand New Infrastructure}

In an environment that demands rapid collection of continuous data to monitor everchanging needs, the ability to quickly deliver those indicators in a format that supports data driven action, and offers a real time granularity that allows funders to see fluctuations not in terms of years but rather months, the US public data infrastructure on which most place-based funders and their community indicator projects rely is woefully inadequate. The United States public health system, however, is a shining example of how that infrastructure can be adjusted so as to respond to threats of pandemic proportions. While this largely solves the problem of the first wave of need hitting our communities, that of an insidious and highly contagious virus, it does not address the secondary effects of this pandemic such as a devastated 
economy that has disproportionately hurt those in greatest need buy eviscerating their jobs and taking a wrecking ball to the support systems such as childcare, housing, transportation and education that had previously helped them make ends meet. In addition, it has threatened new dangers such as increased mental health needs and potential increase in domestic violence.

All of these challenges notwithstanding, this is far from a hopeless case. Communities have the ability to emulate many of the same practices used in the public health sector during the COVID-19 pandemic to address the same needs. Furthermore, this does not need to be expensive. Rather, the key element that is needed is robust collaboration, an area in which place-based funders have notoriously taken a leadership role (CF Leads, 2013).

What would such an infrastructure look like? While the answer could be different for each community, we turn to Syracuse, New York as one example of the technical aspects of how this can be done in a cheap, efficient manner.

\section{Syracuse's Life Needs Assessment - a Pre-Existing Community Poll Realizing Added Utility in the Face of a Pandemic}

In 2017 Syracuse, New York set out to build a real time collaborative data infrastructure (Ridzi, 2020). The Life Needs Assessment is a community project that includes multiple organizations asking the same series of questions (about basic needs such as housing, food, safety and employment) and sharing their results with each other while protecting the confidentiality of their clients. The Central New York Community Foundation helped these organizations with the technical aspects of sharing these data and each organization participates freely for as long as they desire. Organizations participating agree to collect at least 100 surveys annually and in return gain access to the entire Life Needs Assessment data set. The data are intended to be used to do community needs assessment, organizational and program planning, program evaluation, assessment of community impact, match-making between organizations, recruitment of clients and other activities designed to benefit the Central New York community.

From the perspective of the Community Foundation, this project promised to fill a gap in community data, and thus knowledge, that existed between organization level program evaluation and broad community indicators that the community had developed. While the community indicators project, www.Cnyvitals.org, offered substantial data to demonstrate community needs as they emerged, and individual organizations were increasingly working to evaluate the effectiveness of the programs they implemented, the Life Needs Assessment promised to offer insight into which organizations were in closest contact with the community members who experienced certain needs and which neighborhoods were the most acutely affected. Furthermore, the same system could be used to track the progress as multiple organizations and other community partners aligned their efforts in collaborations, coalitions and collective impact efforts.

With the onset of Covid the goal of this project did not change but rather the Community Foundation and the broader community was faced with a need to know 
these things quicker, in a more condensed time frame (i.e. data on this month's needs rather than this year's needs) and with an expectation that these data would be deployed after considering a variety of possible community scenarios. The ways in which the Syracuse community quickly pivoted presents promising opportunities to address the data needs of place-based philanthropy when it comes to monitoring and acting to improve community well-being in the COVID era. Specifically, it offers a way forward for those communities seeking to re-tool in order to build the capacity to describe rapidly changing community needs, foster an expedited connection between data analysis and action, and engage in data-based scenario planning.

\section{Capacity to Describe Rapidly Changing Community Needs}

Much like the community indicators project that it was designed to complement, the Life Needs Assessment was initially conceived of on an annual basis. Participating organizations would aim to collect their data over the course of a year with the expectation that they could then use those data to inform discussions about potential collaboration around community needs in the following year. However, with the onset of Covid two things happened simultaneously. First, it became apparent that needs expressed over the course of the year would vary considerably from prior to Covid as compared to afterwards. Furthermore, as Covid unfolded, needs seemed to change rapidly each month as new workplace restrictions and other antivirus strategies were deployed. As a result, the community created a more granular data display that began to show results on a monthly basis. The second thing that occurred was that organizations began to realize that they no longer had the benefit of talking with clients in person and learning about their needs. As a result, they started to rely more on the Life Needs Assessment and administer a greater number of surveys. By way of comparison, halfway through the calendar year, the entire community was on pace to more than double the Life Needs Assessment responses collected in the prior year. The result was a close to real time insight into emerging community needs with data insights that were refreshed on a daily basis. This ability for community members participating in the project to see data immediately was enabled by the online, cloud-based infrastructure on which the Life Needs Assessment was built. As each community organization conducted assessments with their clients through an online portal, their data were immediately de-identified and then added to the overall data set. This data set automatically updated the data dashboards that every participating member who had completed their first 100 surveys had live access to.

The result was a much closer to real time snapshot of community needs as they emerged. For instance, certain needs such as childcare could seem to decline over the summer and then rise back up as people started to figure out their school year plans. Additionally, local nonprofits were able to monitor trends in needs for housing that steadily increased as a statewide moratorium on evictions approached its expiration date (Goehle \& Keaton, 2020). Furthermore, since the assessment is locally controlled, nonprofits had the ability to modify it to delve deeper into areas of concern. For instance, one nonprofit organization used the LNA to explore social isolation during the pandemic and learned that nearly $40 \%$ of their clients said they 
were "spending time alone more often than [they] would like" (PEACE, Inc., 2020, 18). They similarly found that $36 \%$ of surveyed clients lack sufficient technology and internet access, to meet their needs (PEACE, Inc., 2020, 37). While this knowledge was indeed helpful to the organizations participating, who were able to commit to further working to secure technology and reduce social isolation, perhaps most important to place-based funders however, is the ability to see how basic needs such as food and jobs were changing among the nonprofit network that they support through their grant making, convening and capacity building efforts.

\section{Foster an Expedited Connection Between Data Analysis and Action}

When it comes to data driven philanthropy, collecting data and making it publicly available is only the first half of the battle. Moving rapidly to action is the critical next step. The Covid pandemic situation seemed to be unfolding on a day to day basis and funders were expected to take rapid action. But how fast is fast enough? And is it possible to act too quickly?

Leaders have cautioned the public to wait with patience to see how trends develop by using such things as seven day averages for new daily cases or making decisions based on trends over a few weeks (CNN, 2020b). In practical terms the generally accepted 14 day quarantine rule - due to conservative estimates that the virus has a 14 day incubation period between exposure to the virus and onset of symptoms in most cases (CDC, 2020; Wamsley \& Simmons-Duffin, 2020) - might serve to define the timeframe for analysis to action. In order to notice a trend that is worth acting upon, communities need a baseline of data. Based on the incubation period it would naturally take approximately 14 days before massive exposure would become visible as a spike in health indicators such as COVID cases and hospital admittances. Similarly, the effects of taking evasive action (such as closing schools and parks, enforcing working from home for all but essential workers and mandating the wearing of masks) would take another 14 days approximately before we would see the spike in COVID cases level off or start to decline. The de facto timeline for data analysis to action and then evaluation of effectiveness may thus be in the rough neighborhood of a month.

In the case of Syracuse and its continuous polling through the Life Needs Assessment a similar timeline developed. Data were being collected and added daily through the automated system but tracking responses to the community need survey on a daily basis proved too granular a level. Responses would fluctuate wildly depending on who happened to complete the poll that day. However, when viewed in a zoomed out way, on a month to month average, the data fluctuations became less erratic and patterns became more clear. This empowered local funders with data that would give them a snapshot of how things were going on a month to month basis as they made grant awards decisions.

In Syracuse, as in many communities across the nation (Lilly Family School of Philanthropy, 2020) the local, place-based funders banned together to contribute to a COVID-19 relief fund. The Central New York Community Foundation, in partnership with United Way of Central New York, Allyn Foundation, The Dorothy and 
Marshall M. Reisman Foundation, Health Foundation for Western \& Central New York, the City of Syracuse and Onondaga County established a COVID-19 Community Support Fund (Central New York Community Foundation, 2020). In the words of this coalition of funders their role was clear, "Collaboratively we are rapidly deploying resources to support nonprofit organizations who are helping those disproportionately impacted by the consequences of the coronavirus pandemic" (Central New York COVID-19 Community Support Fund, 2020). Given the data infrastructure noted above, they also had the tools at their disposal to be data driven and to allocate more funding to community needs as they surged and reduce funding as needs subsided. Following this approach, the relief fund deployed the funds it had raised at a much more rapid pace then would be seen under typical grantmaking scenarios, awarding grants multiple times per month rather than on a quarterly or biannual basis. Furthermore, these grants were able to target acute community needs that were related to evolving community situations. While initial grants focused on basic needs such as food, diapers, hygienic products and personal protective gear, later grants focused on helping to move vital services such as counseling, healthcare and crisis hotlines into the virtual environment by investing in digital technology. Having responded to these first and second order needs, grantmaking then turned to helping support the struggling workforce by underwriting the cost of personal safety protection gear and helping to retrofit workplaces and other key in-person services such as childcare for essential workers (Central New York COVID-19 Community Support Fund, 2020).

\section{Engage in Data-Based Scenario Planning}

Predicting the future has never been an easy undertaking, but prior to COVID-19 it seemed fairly plausible to forecast that next year's community indicators data would tend to look very much like this year. This is no longer the case. While there are certainly a variety of speculative approaches that place-based funders can use, such as identifying drivers of client demand (Waldron et al., 2020), data-driven scenario planning tends to require the collection of historical data followed by a factoring in of anticipated possible future events that could cause past trends to change (Bradfield et al., 2005). While expert judgement is still needed to gauge the likelihood of future events (such as emergence of a vaccine or extension of unemployment benefits) that might disrupt historical patterns, trend impact analysis approaches are data driven at their heart (Bradfield et al., 2005).

When it comes to place-based philanthropy, using historical trends to estimate future magnitude of need can be of critical utility. In plain terms, funders need to decide how much of their funding to devote to one community need (such as food) and how much to devote to others (such as helping mental health services transition to online formats). Since some of these needs are more basic (i.e. lower on Maslow's hierarchy of needs), funders will want to be certain that they spend enough on first order needs such as food before turning to other needs. In the case of the Life Needs Assessment, funders and nonprofits alike had a real time insight into what the current need was and whether current funding 
levels were sufficient to keep that need at an acceptable level. For instance, a community that noticed a rise in need for food could direct funding to the food distribution network. Once they saw that this need was met, they could reduce those funds and concentrate on higher order needs, always being sure to keep an eye on food needs in case they resurged. Indeed, according to one analysis, this was the situation in Syracuse where they cited the LNA to assert that: "evidence exists that -overall- the measures pursued by the community at large have helped to limit basic food insecurity needs beyond the first month of the pandemic. For example, between 11 to 22 May 2020, when Life Needs Assessment participants were asked "Do you have enough food," only $9.7 \%$ of the 227 surveyed agency's clients said no." (PEACE, Inc., 2020, 21).

When it comes to scenario planning that focuses on how best to spend philanthropic funds, having a sense of the extent to which current efforts have been successful in abating pressing community needs is critical. Armed with this type of data, place-based funders are much better equipped to gameplan the various scenarios that Deloitte's Monitor Institute laid out (Kasper \& Marcoux, 2020). Faced with an opportunity to make lasting systems change such as through funding the re-design of a work training system for instance, philanthropy will have a better sense based on the current balance of spending and community needs as to how much "dry powder" they should keep in reserve should real life approximate one of the worst case scenarios (Kasper \& Marcoux, 2020, 12).

Furthermore, because the LNA is not an anonymous survey, it allows for local actors to reach out to their clients to further probe their responses and learn first hand about the dynamics underlying certain needs and the level of precarity that community members are facing. As one nonprofit organization using the LNA writes:

"Data provides us with important markers of vulnerability. But as a community, we need to be steadfast in complimenting data-especially when faced with the shortage of it- with the lived and shared experiences of those most vulnerable at this time. A balanced approach must be a holistic one that yields greater insight and meets need. Upon speaking to a Senior who was one of the $9.7 \%$ identified as food insecure in our Life Needs Assessment Survey, we discovered that the senior's inability to visit a now cancelled congregate meal site not only precipitated his current nutrition struggles but also furthered isolation and loneliness. Disruptions and changes don't target one designated pain or trauma. They further multiple vulnerabilities." (PEACE, Inc. 2020, 38)

This level of outreach assists with future scenario planning and opens the door to human centered design approaches for responsive programming; it is also consistent with the Council on Foundations' call to action which included: "Commit to listening to our partners and especially to those communities least heard, lifting up their voices and experiences to inform public discourse and our own decision-making so we can act on their feedback." (Council on Foundations, 2020). 


\section{Implications for Practice}

Perhaps one of the greatest successes of the Syracuse experience was peace of mind. Amidst the chaos and confusion of an abruptly unfolding pandemic, one of the scariest side effects was a feeling of being "in the dark". There was so much speculation about how the pandemic would unfold and the myriad ways its secondary side effects and unforeseen latent manifestations would cause stressors and dangers in the daily life of community residents. However, there was little clarity about how many of these potential negative side effects were actually occurring. For instance, media hype about the need for food and a potential spike in food insecurity highlighted this as a potential catastrophe in the making. However, the Life Needs Assessment data seemed to suggest that in fact need was not spiking as had been anticipated. Rather, these data suggested that food need was largely being addressed. The presence of these data and seeming contradiction with national news media hype and images of long lines at food pantries lead to further investigation and discussion with food distribution professionals and even follow-ups with individuals who had completed the Life Needs Assessment. What we learned was that our community's local food distribution network was indeed robust and, thanks to federal relief funding and generous local donations to food pantries and other food distribution systems, our local need had been well addressed. This is one example of a broader experience in which having an ongoing pulse of the community proved helpful to local funders as they sought to triangulate this data source with other historically available data such as reaching out to experts and looking at government supported indicators.

The converse of this experience was that recognizing when certain community needs were being kept at bay allowed for local actors to instead conserve and redirect their energies toward issues that were not being adequately addressed. For instance, unemployment soared during this time and there were alarming levels of people reporting that they could not pay their bills or save for future needs. This prompted extra efforts to reinforce a nascent network focused on financial empowerment and such things as helping the unbanked connect with financial institutions, reducing debt burdens, and increasing personal financial literacy. Furthermore, insights provided by the Life Needs Assessment allowed for enhanced efforts to make connections between the growing number of local unemployed and the paradoxically persisting supply of unfilled jobs.

The Syracuse experience has shown us that a robust infrastructure, once built, is remarkably easy to maintain without requiring extensive financial or other resources. Furthermore, the buy-in of local organizations that have continued to use this approach without the need for continued foundation funding makes the case that this approach has a value added for all involved. As such, it suggests that this form of a real time data collection connected with rapid shifting of funder focus is an approach that can persist well after the pandemic has subsided.

One critical lesson learned is that dashboards themselves have limitations. Simply relying on quantitative trend lines is insufficient to fully comprehend the details and nuances of the hurdles that people face in a rapidly changing world. 
As a counterbalance, Syracuse relied on the fact that it's Life Needs Assessments were not done anonymously but rather confidentially. While data were deidentified before being shared across organizations in the community, the system allowed for the critical functionality of being able to reach out to caseworkers whose clients had expressed a specific pattern of needs. These caseworkers then were able to reach out to their own clients in order to figure out what was going on behind the numbers. This proved essential in figuring out the nuances behind otherwise confusing data trends. This connection between funders recognizing a broad need in the community and nonprofits recognizing the shared need among their own clients is an essential dynamic for funders who seek to move from data to action. Since funders do not tend to have their own direct connection with residents in their communities who are in need of services the buy-in of and collaboration with nonprofit direct service providers is vital. While the Syracuse example is unique in that it had a strong foundation of collaboration around data sharing in place and a vibrant history of technological innovation in this area, there is little in the way of barriers that would prevent other communities from following suit. The Life Needs Assessment was built in the free Google G-suite platform so can be built and replicated at virtually no cost in other communities. Technological know-how and computer programming skills are perhaps the largest barrier to replication in other communities since a variety of data confidentiality safeguards need to be put in place. However, as far as technology goes, being able to produce such a robust system without any software or hardware expenses is a welcome anomaly. In effect, the Syracuse experience give us a reason to hope that in the near future other cities can enjoy the benefits of real-time data for funders and the nonprofits that serve the community.

\section{Conclusion}

The COVID-19 pandemic has led communities across the globe to rethink the way they do things and seek ways to adapt to a new normal. When it comes to placebased funders that are seeking to keep their finger on the pulse of their communities through using community indicator data, the Covid era has introduced a new gold standard for what it means to have timely data, take urgent action, and engage in reasonable scenario planning for future eventualities. These new expectations, although in many ways accelerations of trends that have already been in progress, present a challenge to place-based funders because typical community indicator projects are ill-equipped to meet the standards.

Nevertheless, local data collection efforts designed to complement community indicator work, such as that seen in Syracuse, New York, offer a potential blueprint for communities that are seeking inexpensive and rapidly deployable ways to adjust to a new normal. By building a local infrastructure that provides real time, widely shared, and automatically updated polling of community member needs, place-based funders as well as their other community partners can rise to this new challenge. 


\section{Declarations}

Conflict of Interest On behalf of all authors, the corresponding author states that there is no conflict of interest.

\section{References}

Barrington-Leigh, C. (2017). The Role of Subjective Well-Being as an Organizing Concept for Community Indicators. In: Holden M., Phillips R., Stevens C. (eds) Community Quality-of-Life Indicators: Best Cases VII. Community Quality-of-Life and Well-Being. Springer, Cham. https://doi.org/10.1007/ 978-3-319-54618-6_2

Ken, B., \& Joe D. (2020). The Draft Filled a Void, But What Happens Next?". Page 33. New York Times Magazine Sunday April 26, 2020.

Bradfield, R., Wright, G., Burt, G., Cairns, G., \& Van Der Heijden, K. (2005). The origins and evolution of scenario techniques in long range business planning, Futures, 37(8), 2005. ISSN, 795-812, 0016-3287. https://doi.org/10.1016/j.futures.2005.01.003

CDC. (2020). When to Quarantine. Centers For Disease Control And Prevention: Coronavirus Disease 2019 (COVID-19). Retrieved December 20, 2020, from https://www.cdc.gov/coronavirus/2019ncov/if-you-are-sick/quarantine.html

Central New York Community Foundation. (2020). The COVID-19 Community Support Fund. Retrieved December 20, 2020, from Retrieved December 20, 2020, from https://cnycf.org/covid19\#.X4CcVNBKjIU

Central New York COVID-19 Community Support Fund. (2020). Purpose of the Fund. Retrieved December 20, 2020, from https://cnysupportfund.org/\#purpose

CF Leads. (2013). "Framework for Community Leadership by a Community Foundation." Created by the National Task Force on Community Leadership Prepared by CFLeads and Aspen Institute Community Strategies Group Retrieved April 23, 2017, from https://cfleads.org/wp-content/uploads/2019/ 10/CFLeads-Framework-1.pdf

CNN Wire. (2020). Top doctor says White House coronavirus task force still missing 50\% of testing data. Posted: Apr 3, 2020 / 06:16 AM CDT / Updated: Apr 3, 2020 / 06:16 AM CDT, News Channel 3, WREG Memphis. Retrieved December 20, 2020, from https://wreg.com/news/top-doctor-sayswhite-house-coronavirus-task-force-still-missing-50-of-testing-data/

CNN. (2020b). Leaders in several states warn residents to be on guard as worrying COVID-19 trends emerge. Channel 7 News Boston. WHDH-TV OCTOBER 1, 2020. Retrieved December 20, 2020, from https://whdh.com/news/leaders-in-several-states-warn-residents-to-be-on-guard-asworrying-covid-19-trends-emerge/

Community Indicators Consortium. (2020). CI-PM Integrations. Retrieved December 20, 2020, from https://communityindicators.net/research/ci-pm-integrations/

Council on Foundations. (2020). "A Call To Action: Philanthropy's Commitment During Covid19." Retrieved December 20, 2020, from https://www.cof.org/news/call-action-philanthropyscommitment-during-covid-19

Crawford J., Ridzi F. (2020) Meaningful, Manageable, and Moveable: Lessons Learned from Building a Local Poverty Index. In: Ridzi F., Stevens C., Davern M. (eds) Community Quality-of-Life Indicators. Community Quality-of-Life and Well-Being. Springer, Cham. https://doi.org/10.1007/ 978-3-030-48182-7_5

Davern M., Buckley P.D., Bucello P. (2020) Indicators Supporting Public Health, Partnership, Liveability and Integrated Planning Practice: The Case Study of the Cardinia Shire Growth Area in Melbourne, Australia. In: Ridzi F., Stevens C., Davern M. (eds) Community Quality-of-Life Indicators. Community Quality-of-Life and Well-Being. Springer, Cham. https://doi.org/10.1007/978-3-030-48182-7_7

Delaney, T. (2020). Warning Signs About the Fragility of Nonprofits in the Pandemic Era. November 12, 2020. National Council of Nonprofits. Retrieved March 22, 2020, from https://www.councilofn onprofits.org/thought-leadership/warning-signs-about-the-fragility-of-nonprofits-the-pandemic-era

Goehle, T., \& Keaton, O. (2020). What is Rent Burden? Housing Instability and Hyper-Segregation in Central New York. Peace Inc. October 2020. Retrieved December 20, 2020, from https://www. peace-caa.org/wp-content/uploads/2020/10/October_Housing_White_Paper_Final.pdf 
Idli, L. (2020). Cuomo: New York Now Has More Than Half Of Coronavirus Cases in U.S. After Surge Of 5,000 Cases. Media Ite, MSNBC broadcast. Mar 23rd, 2020, 12:40 pm. Retrieved December 20, 2020, from https://www.mediaite.com/tv/cuomo-new-york-now-has-more-than-half-of-coron avirus-cases-in-u-s-after-surge-of-5000-cases/

Hopkins J. (2020). Coronavirus Resource Center. Retrieved December 20, 2020, from https://coronavirus.jhu.edu/map.html

Kasper, G., \& Marcoux, J. (2020). An event or an era? Resources for social sector decision-making in the context of COVID-19 July 2020. Monitor Institute by Deloitte. Retrieved December 20, 2020, from https://www2.deloitte.com/content/dam/Deloitte/us/Documents/about-deloitte/us-monitor-institutescenarios-for-the-social-sector-493768.pdf

Katz, S.N. (2005). "What does it mean to say that philanthropy is" effective"? The philanthropists' new clothes." Proceedings of the American Philosophical Society 149, no. 2 (2005): 123-131.

King L.O. (2017) Comprehensive Sustainability Indicators: The Houston Sustainability Indicators Program. In: Holden M., Phillips R., Stevens C. (eds) Community Quality-of-Life Indicators: Best Cases VII. Community Quality-of-Life and Well-Being. Springer, Cham. https://doi.org/10.1007/ 978-3-319-54618-6_10

Korn, M., Belkin, D., \& Chung, J. (2020). Colleges pushed to breaking point --- pandemic is expected to hit enrollment and revenue, forcing 'hard choices' about education. Wall Street Journal Retrieved December 20, 2020, from https://www.wsj.com/articles/coronavirus-pushes-collegesto-the-breaking-point-forcing-hard-choices-about-education-11588256157

Leonard, J. (2014). Merging money and mission: becoming our community's development office. In T. Mazany and D. Perry (Eds.), Here for good community foundations and the challenges of the $21 \mathrm{st}$ century (pp. 107-122). New York M.E. Sharp.

Lilly Family School of Philanthropy. (2020). "Response and relief funds by U.S. community foundations and United Ways.'Indiana University. Retrieved December 20, 2020, from https://philanthropy.iupui. edu/research/covid/foundations.html

Maslow, A. H. (1943). A theory of human motivation. Psychological Review, 50(4), 370-396.

Mazany, T., \&Perry, D. (2014). (Eds.), Here for good community foundations and the challenges of the 21st century. New York M.E. Sharp. http://117.211.153.211:8001/jspui/bitstream/12345 6789/236/1/0765642557.pdf

McCartney, R. (2020). "Nonprofits in trouble: One-third of organizations may not survive pandemic, recession." August 3, 2020 at 5:01 a.m. EDT. The Washington Post. Retrieved March 22, 2021, from https://www.washingtonpost.com/local/non-profits-coronavirus-fail/2020/08/02/ef486 414-d371-11ea-9038-af089b63ac21_story.html

Moriarty, R. (2020). Coronavirus: Task force to help Syracuse-area businesses survive 'staggering' downturn. Syracuse.Com. Updated Apr 07, 2020; Posted Mar 25, 2020. Retrieved December 20, 2020, from https://www.syracuse.com/coronavirus/2020/03/coronavirus-task-force-to-help-syrac use-area-businesses-survive-staggering-downturn.html

New York Council of Nonprofits. (2019). "Nonprofit 'Then \& Now' Landscape, Changes in the COVID19 Era”. All Rights Reserved; New York Council of Nonprofits, Inc. Retrieved December 20, 2020, from www.nycon.org

New York Times. (2020). "Monitoring the Coronavirus Outbreak in Metro Areas Across the U.S." Updated October 3, 2020, 1:59 P.M. E.T. Retrieved December 20, 2020, from https://www.nytimes. com/interactive/2020/04/23/upshot/five-ways-to-monitor-coronavirus-outbreak-us.html

Patten, M., \& Lyons, S. (2009). Vital signs: Connecting community needs to community philanthropy in Canada. The Philanthropist, 22, 56-61.

PEACE, Inc. (2020). A COVID-19 Community Needs Chronicle and Assessment for Syracuse and Onondaga County, New York. Prepared by the Community Engagement Department of PEACE, Inc. June 22, 2020. Retrieved December 20, 2020, from https://www.peace-caa.org/about-us/covid19-community-chronicle-and-needs-assessment/

Perez, S. (2020). "COVID-19 pandemic accelerated shift to e-commerce by 5 years, new report says." Tech Crunch. Published 11:42 AM EDT. August 24, 2020. Retrieved December 20, 2020, from https://techcrunch.com/2020/08/24/covid-19-pandemic-accelerated-shift-to-e-comme rce-by-5-years-new-report-says/

Petrock, V. (2020). "How COVID-19 Is Fast-Tracking Emerging Tech Innovations Show Renewed Promise During Pandemic." eMarketer inc Apr 6, 2020. Retrieved December 20, 2020, from https://www. emarketer.com/content/how-covid-19-is-fast-tracking-emerging-tech 
Powell, J. (2020). A tale of three cities: Five conditions conducive to sustainability plans and measurements. In F. Ridzi, C. Stevens, \& M. Davern (Eds.), Community quality-of-life indicators: Best cases VIII. (pp. 137-162). Springer.

Ridzi, F. (2012). Managing expectations when measuring philanthropic impact: A framework based on experience. The Foundation Review, 4(4), 98-109.

Ridzi F. (2020) Goldilocks Data-Connecting Community Indicators to Program Evaluation and Everything in Between. In: Ridzi F., Stevens C., Davern M. (eds) Community Quality-of-Life Indicators. Community Quality-of-Life and Well-Being. Springer, Cham. https://doi.org/10.1007/978-3-030-48182-7_2

Ridzi, F., \& Prior, T. (2020). "Community Leadership through Conversations and Coordination: The role of local surveys in community foundation run community indicators projects." International Journal of Community Well-Being. Retrieved December 20, 2020, from https://link.springer.com/article/ 10.1007\%2Fs42413-020-00098-z

SeaChange. (2020). Tough Times Call For Tough Action: A Decision Framework For Nonprofit Leaders \& Boards. March 31, 2020. Retrieved December 20, 2020, from http://gd7xi2tioeh408c7o347 06rc-wpengine.netdna-ssl.com/wp-content/uploads/2020/04/COVID-19-Nonprofit-Decision-Frame work.pdf

Stevens, C., deBlois, M., Hamberg, R., \& Baldwin, J. (2019). Community Indicators Project Development Guide. https://www.Amazon.com

Summers K., Salazar V., Olszyk D., Harwell L., Brookes A. (2020) The Development of DISC (Decision Integration for Strong Communities): An Agile Software Application of Sustainability Indicators for Small and Rural Communities. In: Ridzi F., Stevens C., Davern M. (eds) Community Qualityof-Life Indicators. Community Quality-of-Life and Well-Being. Springer, Cham. https://doi.org/10. 1007/978-3-030-48182-7_6

Syracuse-Onondaga County Planning Agency. (2020). Onondaga County, NY COVID-19 Cases by Municipality. (as of October 2, 2020). Retrieved December 20, 2020, from https://socpa.maps.arcgis.com/apps/opsdashboard/index.html\#/7bd218bc8be04b209c0b80a83fc2eba5

Tingley, K. (2020). Coronavirus Is Forcing Medical Research to Speed Up. New York Times Magazine. April 26, 2020. P16-18. April 21, 2020 online. Retrieved December 20, 2020, from https://www.nytimes.com/2020/04/21/magazine/coronavirus-scientific-journals-research.html

Volz, B., Shultz, R., Baglietto Isabella Gupta Inda. (2019). Onondaga County Community Health Assessment and Improvement Plan 2019-2021. Retrieved December 20, 2020, from http://www.ongov.net/ health/documents/OnondagaCountyCHA-CHIP.pdf

Waldron, L., Robert S,. \&Jaskula-Ranga, A. (2020). Making Sense of Uncertainty: Nonprofit Scenario Planning in the COVID-19 Pandemic. Bridgespan Group. May 2020. Retrieved December 20, 2020, from https://www.bridgespan.org/insights/library/strategy-development/nonprofit-scenario-plann ing-covid-19

Wamsley, L., \& Simmons-Duffin, S. (2020). The Science Behind A 14-Day Quarantine After Possible COVID-19 Exposure. National Public Radio. April 1, 2020 1:45 PM ET. Retrieved December 20, 2020, from https://www.npr.org/sections/health-shots/2020/04/01/824903684/the-science-behind-a14-day-quarantine-after-possible-covid-19-exposure

Whelan, R. (2020).Troubled Covid-19 Data System Returning to CDC. The Wall Street Journal. Updated Aug. 20, 2020 2:04 pm ET. Retrieved December 20, 2020, from https://www.wsj.com/articles/troub led-covid-19-data-system-returning-to-cdc-11597945770

Wilkinson, A., \& Kupers, R. (2013). Managing Uncertainty: Living in the Futures Harvard Business Review. May 2013 Issue. Retrieved December 20, 2020, from https://hbr.org/2013/05/living-in-thefutures

Zolli, A. (2020). "Toward A New Pact Between Tech, Humanity and the Planet". Tue May 19, 2:00 PM 6:00 PM CDT / 3:00 PM - 7:00 PM Your local time (4 Hours). Good Tech Fest. Keynote 3:30-4:15.

Publisher's Note Springer Nature remains neutral with regard to jurisdictional claims in published maps and institutional affiliations. 